\title{
Correction to: Exergy analysis of direct-expansion solar-assisted heat pumps working with R22 and R433A
}

\author{
L. Paradeshi $^{1} \cdot$ M. Mohanraj ${ }^{2} \cdot$ M. Srinivas ${ }^{1} \cdot$ S. Jayaraj ${ }^{1}$
}

Published online: 28 September 2018

(C) Akadémiai Kiadó, Budapest, Hungary 2018

\section{Correction to: Journal of Thermal Analysis and Calorimetry https://doi.org/10.1007/s10973-018-7424-3}

The article Exergy analysis of direct-expansion solar-assisted heat pumps working with R22 and R433A, written by L. Paradeshi, M. Mohanraj, M. Srinivas, S. Jayaraj, was originally published electronically on the publisher's internet portal (currently SpringerLink) on 13, June 2018 with open access.

With the author(s)' decision to step back from Open Choice, the copyright of the article changed on 22, September 2018 to (C) Akadémiai Kiadó, Budapest, Hungary 2018 and the article is forthwith distributed under the terms of copyright. The original article has been corrected.

The original article can be found online at https:// doi.org/10.1007/s10973-018-7424-3.

L. Paradeshi

lokeshpb@gmail.com

1 Department of Mechanical Engineering, National Institute of Technology, Calicut, India

2 Department of Mechanical Engineering, Hindusthan College of Engineering and Technology, Coimbatore, India 